\title{
Epidural Cement Leakage During Kyphoplasty Leading to RADICULOPATHY
}

\author{
Ivan Urits, MD', George Chesteen, MD $^{2}$, Vwaire Orhurhu, MD', Alan D Kaye, MD, PhD $^{3}$, and \\ Omar Viswanath, MD ${ }^{4-6}$
}

Percutaneous vertebroplasty and balloon kyphoplasty are effective minimally invasive methods of treating osteoporotic vertebral compression fractures (VCF) (1). Though generally regarded as safe, commonly encountered complications include polimethylomethylacrylate (PMMA) cement leakage into adjacent tissues, paravertebral vein embolism, intradiscal PMMA leakage, and intraspinal PMMA leakage (2). In a study of 1100 vertebroplasties, nearly $50 \%$ developed complications; however, fewer than $5 \%$ of which produced clinical symptoms. A single intraspinal leakage of PMMA cement was reported $(0.8 \%)$, which required surgical decompression (2). Similarly, in a prospective study of 100 patients receiving kyphoplasty, a cement leakage rate of $61 \%$ was reported, though only 1 incidence of intravascular leakage required further surgical management (3). Our patient is a 84-year-old female, status post T7 kyphoplasty who presented with upper back pain radiating into her left scapula. She also reported abdominal radicular pain as well. Subsequent computed tomography (CT) imaging (Fig. 1) demonstrated epidural leakage of implanted PMMA cement, requiring surgical decompression. PMMA cement leakage is a common complication of balloon kyphoplasty and vertebroplasty. Though rare in presentation, cement leakage into the epidural space may occur requiring urgent physician recognition and management.

From : ${ }^{1}$ Beth Israel Deaconess Medical Center, Department of Anesthesia, Critical Care, and Pain Medicine, Harvard Medical School, Boston, MA; ${ }^{2}$ Barrow Neurological Institute, Phoenix, AZ; ${ }^{3}$ Louisiana State University Health Sciences Center, Department of Anesthesiology, New Orleans, LA; ${ }^{4}$ Valley Anesthesiology and Pain Consultants, Phoenix, AZ; ${ }^{5}$ University of Arizona College of Medicine - Phoenix, Department of Anesthesiology, Phoenix, AZ; ${ }^{6}$ Creighton University School of Medicine, Department of Anesthesiology, Omaha, NE

Author for correspondence: Ivan Urits, MD

Address: Beth Israel Deaconess Medical Center, William Arnold-Carol A. Warfield, MD Pain Center, 1 Brookline Place, Suite 105, Brookline, MA, 02445-7224

E-mail: Iurits@bidmc.harvard.edu

Disclaimer: There was no external funding in the preparation of this manuscript. Conflict of interest: Each author certifies that he or she, or a member of his or her immediate family, has no commercial association (i.e., consultancies, stock ownership, equity interest, patent/licensing arrangements, etc.) that might pose a conflict of interest in connection with the submitted manuscript. 


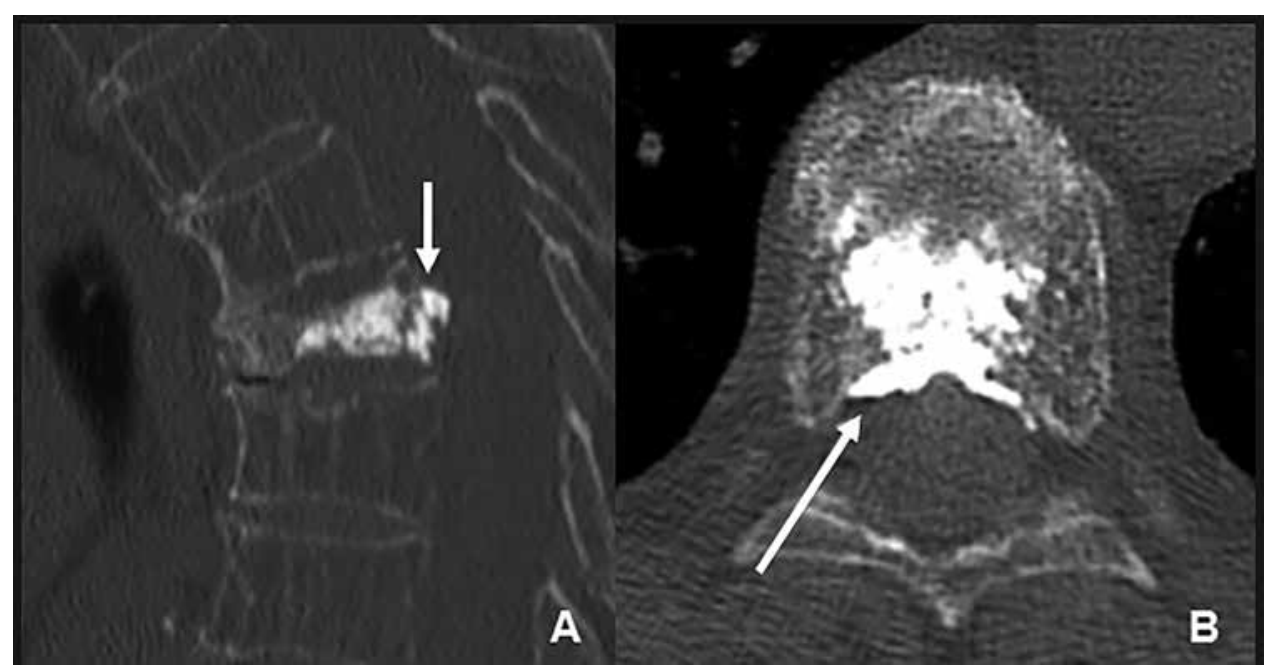

Fig. 1. Sagittal (A) computed tomography (CT) image demonstrating protruding epidural leakage of polimethylomethylacrylate (PMMA) cement used during kyphoplasty of an atraumatic vertebral compression fracture causing axial back pain. Axial (B) CT image demonstrating bilateral epidural spread of PMMA cement leakage.

\section{REFERENCES}

1. Yuan W-H, Hsu H-C, Lai K-L. Vertebroplasty and balloon kyphoplasty versus conservative treatment for osteoporotic vertebral compression fractures. Medicine (Baltimore) 2016; 95:e4491.

2. Saracen A, Kotwica Z. Complications of percutaneous vertebroplasty. Medicine (Baltimore) 2016; 95:e3850.

3. Riesner H-J, Kiupel K, Lang P, Stuby F, Friemert B, Palm H-G. Clinical relevance of cement leakage after radiofrequency kyphoplasty vs. balloon kyphoplasty: A prospective randomised study. Z Orthop Unfall 2016; 154:370-376. 